\title{
Assessing the effect of knowledge inertia on corporate knowledge sharing and strategic learning capabilities
}

\author{
Tahereh Rezaee \\ Department of Management, Malayer Branch, Islamic Azad University, Malayer, Iran \\ taherehrezaee@gmail.com
}

\section{Zahra Shirazian}

Assistant Professor and Faculty Member, Department of Management, Malayer Branch, Islamic Azad University, Malayer, Iran

zahra.shirazian@gmail.com

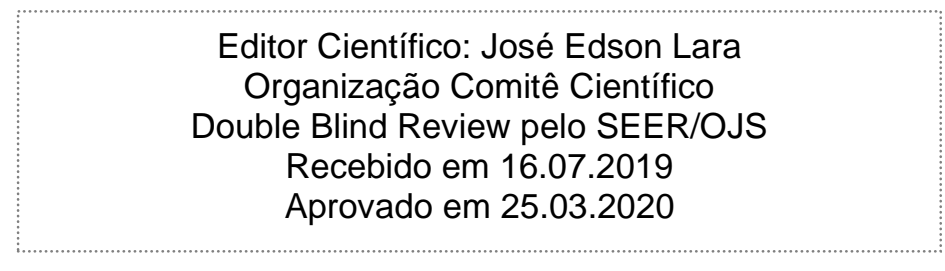

\section{(c) (i) (8)}

Este trabalho foi licenciado com uma Licença Creative Commons - Atribuição - Não Comercial 3.0 Brasil 


\begin{abstract}
The current study was conducted with the aim of investigating the effect of knowledge inertia on corporate knowledge sharing capabilities and strategic learning capabilities at the National Bank branches of Hamedan Province. This research consists of a descriptive, quantitative, applied and cross sectional study. The statistical population consists of the entire Hamedan Province National Bank branch personnel which were 610 people. From this population, 240 were selected based on the Krejcie and Morgan table using stratified random sampling. The data required for this study was gathered using standard questionnaires which were reviewed and validated. In order to analyze the data, structural path analysis and SmartPLS software was used. The results of this research confirm the significant effect of knowledge inertia on knowledge sharing capabilities and their components on corporate strategic learning capabilities. Moreover, the findings show that knowledge inertia and its components have a significant effect on the strategic learning capabilities of the organization.
\end{abstract}

Keywords: knowledge inertia, knowledge sharing capabilities, organization strategic learning capabilities

\title{
Avaliando o efeito da inércia do conhecimento no compartilhamento corporativo de conhecimento e nas capacidades de aprendizado estratégico
}

\section{Resumo}

O presente estudo foi conduzido com o objetivo de investigar o efeito da inércia do conhecimento nas capacidades de compartilhamento de conhecimento corporativo e de aprendizagem estratégica nas agências do Banco Nacional da província de Hamedan. Esta pesquisa consiste em um estudo descritivo, quantitativo, aplicado e transversal. A população estatística é composta por todo o pessoal da agência do Banco Nacional da Província de Hamedan, que era de 610 pessoas. Dessa população, 240 foram selecionados com base na tabela de Krejcie e Morgan usando amostragem aleatória estratificada. Os dados necessários para este estudo foram coletados usando questionários padrão, que foram revisados e validados. Para análise dos dados, utilizou-se a análise do caminho estrutural e o software SmartPLS. Os resultados desta pesquisa confirmam o efeito significativo da inércia do conhecimento nas capacidades de compartilhamento de conhecimento e seus componentes nas capacidades de aprendizagem estratégica corporativa. Além disso, os resultados mostram que a inércia do conhecimento e seus componentes têm um efeito significativo nas capacidades estratégicas de aprendizagem da organização.

Palavras-chave: inércia do conhecimento, recursos de compartilhamento de conhecimento, recursos de aprendizado estratégico da organização 


\section{Introduction}

Organizational learning and knowledge management are two concepts that were concurrently introduced in the modern era and are sometimes referred to one another in various definitions and activities (Shahabi and Jalilian, 2012). Organizational learning is a decisive factor in the long term performance and survival of an organization (Yukl, 2009). It is an effective factor for organizational success as well as a source for competitive advantage (Bhatnagar, 2006). Furthermore, in the knowledge management field, a concept is introduced called knowledge inertia which can obstruct the organization's capability in learning and resolving issues. Knowledge is of strategic importance for organizations as a source of power. Inertia may lead to a lack of innovation and relevant behavior which may jeopardize the organization's survival or severely undermine the organization's advantage in a highly competitive environment; thus it is vital for organizations to avert the negative effects of inertia on its learning capabilities and to effectively and efficiently apply organizational knowledge (Xie et al, 2015). An assessment of scientific literature indicates that the role of knowledge inertia in regard to corporate strategic learning has remained neglected. Moreover, the findings of the study confirm that concerning relevant literature, attention has not been focused on knowledge inertia in regard to the knowledge sharing capabilities of organizations. In this vein, the following study attempts to cover such gap and aims to answer the question of whether knowledge inertia has a significant effect on knowledge sharing and strategic learning capabilities.

\section{Research necessity and importance}

Inertia describes the tendency to remain unchanged and resist against organizational strategic refinement outside the existing strategy framework (Liao et al, 2008). Previous experiences which are not refined and updated lead to predictable managerial and strategic behavior for an organization in resolving issues (Liao, 2002). When an organization becomes accustomed to repeatedly implementing similar methods to resolve or confront its issues, it will continuously achieve similar results whilst using analogical reasoning and adaptations for similar conditions with the justification of saving time and avoiding the risk of change; whereas if everything stems from previous knowledge and experience without updates or refinements, the organization's approach to resolving issues will become predictable and based on inertia. 
In such case, in a highly competitive environment, competitors may predict the organization's path, thinking method and implementation process in resolving issues, which can lead to failures or various losses for the organization (Liao, 2002). Thus, the necessity of paying attention to knowledge inertia within the organization can play a vital role in the survival of the organization. On the other hand, only organizations that focus and place emphasis on organizational learning are able to predict the necessities and environmental changes in a timely manner and continue to survive in a continuously changing environment (Kordnaeej et al, 2014). Organizational learning is the most prominent means of improving long-term performance. In the near future, organizations that are competent in optimally utilizing the capabilities and learning capacities of its personnel throughout all its levels can claim dominance. In organizational learning, members of the organization are trained to face potential changes and events through identifying the causes of mistakes prior to correcting them and by learning relevant lessons through such experiences (Peaen et al, 2005). Organizational learning is the product of inquiries and research within the organization. In other words, in the cases where expected consequences of a work process are inconsistent with actual results, an individual or group inquires and researches to perceive the cause of such contradiction and, if necessary, to take measures in resolving such issues. In the process of this organizational inquiry, individuals will interact with other members of the organization, thus resulting in learning. Therefore, learning is a direct product of such interaction (Aarabi and Fakharian, 2009). Organizational learning entails numerous positive outcomes. Some of these include its impact on job satisfaction, the ability to accept and face changes and challenges in addition to the organizational commitment of employees whilst increasing the employees' professional competence (Heydari et al, 2014). Given the significance of organizational learning in knowledge management, organizations should focus their efforts to avert knowledge inertia. Knowledge inertia not only negatively effects the use and application of knowledge within an organization, but may also lead to the disclosure of business secrets and in other words, may lead to losses and eventually the failure of an organization.

\section{Theoretical background of research}

Knowledge inertia 
Knowledge inertia refers to the application of procedures, prior knowledge or experience to resolve issues and seek new knowledge. Inertia refers to everyday trust in procedures and guidelines to resolve issues and manage unprecedented situations (Xie et al, 2015).

Knowledge inertia: refers to reliance on the current knowledge structure, experience and resources when faced with an unprecedented situation or issue to achieve a reaction.

Experience inertia: refers to the learning and acquisition of new knowledge to resolve issues, thus eliminating stagnations in thinking (Xie et al, 2015).

Knowledge inertia and the use of common problem-solving perspectives prevents the acceptance of risks despite saving time and energy (Liao et al, 2008). Knowledge inertia creates barriers in organizational learning, reduces legitimate options, and hinders the development of appropriate strategies. Persistent adverse impacts of organizational inertia may last for decades (Baker and Collins, 2009).

Wang and Yang (2013) investigated the effect of knowledge inertia on individual innovation within an organization whilst classifying the theoretical and empirical literature pertaining to the field of knowledge inertia into three dimensions. In the first dimension, they identified the concepts and phenomena that entail implications for organizational inertia. Wang and Yang believe that in most of the studies conducted up to the year 2013, most researchers have proposed organizational inertia as defined by Liao (2002). In the second dimension, knowledge inertia aspects and components were assessed. According to Wang and Yang, Liao (2002) was the first person to classify knowledge inertia components. Liao (2002) recognized knowledge inertia as the three dimensions of processes inertia, consultancy inertia and experience inertia. In most conducted studies, knowledge inertia consists of experience inertia and learning inertia. Chang and Lin (2011) added a third dimension to knowledge inertia i.e. thinking inertia. They define thinking inertia as: when new ideas are presented in the form of old stereotypes and existing knowledge is used to perceive such new ideas. Extensive studies have also been conducted in the execution field. Xiao et al, 2012 investigated the moderator role of knowledge inertia in the relationship between organization learning and employee suitability within the organization. The results of this study show that both experience inertia and learning inertia aspects reduce the severity of the relationship between organizational learning and suitability. Kafshchi et al, 2012 also examined the effect of individual and organizational factors as well as factors related to information technology in the emergence of 
inertia in employee learning and experience in private and public banks in Iran. Shalikar et al, 2011 investigated the relationship between knowledge inertia and organizational learning as well as organizational innovation and concluded that knowledge inertia has a negative effect on organization innovation and learning.

\section{Knowledge sharing}

Knowledge sharing is one of the most vital components in designing and implementing knowledge management strategies. Knowledge management strategies often involve seven components. These components include the identification, collection, selection, organization, application, sharing and creation of knowledge. Among these seven components, knowledge sharing is the most prominent component (Lin et al, 2012). The objective of establishing a knowledge management scheme and utilizing knowledge as a competitive advantage will only be achieved through the seamless and dynamic sharing of knowledge. All project teams, regardless of their field of activity should develop mechanisms to share knowledge and experiences in order to achieve the specified project plan goals. It is possible to share knowledge as a process of knowledge transfer among individuals, groups and organizations that form information, ideas and relevant content skills (Lee, 2001). Moreover, this expression can also be defined as the exchange of knowledge among organizational units in order to benefit from current or future resources (Lin, 2008). Knowledge sharing is a social phenomenon that involves interpersonal relationships and social interactions (Lin et al, 2012). Knowledge sharing among project team members through knowledge sharing takes place via all internal, external, official, and unofficial channels whilst the purpose of this exchange is to enhance the applied value of knowledge. Knowledge transfer among individuals and project team members involves the dynamic dissemination of knowledge within the project team structure and the acquisition of new knowledge from environmental resources for the project team members (Rosen et al, 2007).

\section{Organizational learning}

Simon defined organizational learning as the development of insights and structure refinement as well as the successful review of organizational issues by individuals, such that results are reflected within structural factors and organizational outcomes (Smith, 2001). 
Nonaka believes that organizational learning results from the repetition of internal and external processes (Oldham, 1996). Dodgeson defines organizational learning as a method for organizations to create, complete and organize to develop normal work flows relevant to activities and to improve organizational efficiency through the utilization of extensive employees' skills (Dooley and Sullivan, 2003). According to Andrew Mayo, organizational learning consists of all the methods, mechanisms and processes utilized within the organization to achieve learning (Moenaert, 2000). Thus, organizational learning can be considered as the ability of the organization as a whole to detect errors and rectify them, as well as change the organization's knowledge and values in order to create new work related problem solving skills and capacities (Sobhaninejad, 2006).

Organizational strategic learning capabilities: this denotes organizational learning from a strategic perspective which allows capacities and competencies to determine whether an organization can continuously pursue its strategic learning (Moon et al, 2017).

\section{Empirical research background}

Aslanlou and Khodami, 2017 conducted a study titled "The effect of knowledge inertia and entrepreneurship intensity on brand performance" and aimed to investigate the influence of internal and external organizational factors on brand performance through a hybrid approach. The results of this study show that organizational innovation and learning capabilities adopt the role of a moderator in the relationship between knowledge inertia and entrepreneurship intensity with brand performance within three dimensions of market-focused learning, relationshipfocused learning and internally-focused learning.

Shahabi and Jalilian (2011) conducted a study titled "The relationship between knowledge inertia, organizational learning and organizational innovation (case study: Western Oil and Gas Company)". The results of this study show that knowledge inertia has a direct effect on organizational learning whilst organizational innovation is directly affected by organizational learning. Furthermore, knowledge inertia indirectly impacts organizational innovation through organization learning.

Heydari et al. (2013) conducted a study titled "Organizational learning capabilities for nurses". The conclusion of this research confirmed that organizational learning takes place at a moderate level. 
Hosseini et al. (2013) conducted a study titled "Assessment of the relationship between knowledge inertia, knowledge management and organizational innovation, case study: small and medium software industry enterprises in Yazd Province". The conclusion of this study confirms that there is a negative relationship between innovation and knowledge inertia and a positive relationship between innovation and knowledge management.

Sepahvand et al. (2018) conducted a study titled "Identification and prioritization of factors that create organizational inertia using a fuzzy Delphi method". This research consisted of a hybrid qualitative and quantitative approach. The statistical population consisted of middle level managers of governmental organizations in Khoramabad city, 30 of which were selected as the sample under evaluation. In this research, by combining qualitative and quantitative methods, initially, by using the acquired qualitative data from exploratory studies, including the assessment of exploratory texts and conducting exploratory interviews, the factors that separate organizational inertia were determined. Then, upon the extraction of these factors, they were subjected to evaluation through survey research. The findings of this research show that fear, conservatism, lack of job security, stress, anxiety, lack of understanding environmental changes, stale thinking, psychological defense and lack of knowledge about the cause of change are the main factors in creating organizational inertia.

Rahnavard et al, (2009) conducted a study titled "The effect of organizational structure, organizational culture and information technology application on knowledge sharing in executive institutions in Isfahan". This was an applied research in terms of cognitive purpose and a descriptive survey research in terms of methodology. The statistical sample of this study consisted of 59 executive bodies and data collection was conducted via a questionnaire. The partial least squares method was used to test the hypotheses. The findings of this study concluded that adaptation, participation and mediated missions, focus on knowledge sharing and information technology application, engagement, mediated information technology, and the involvement of an organizational culture aspect had significant effect on knowledge sharing and formalism.

Hajian and Sardar (2017) conducted a study titled "The presentation of a model to measure internal and external motivational factors affecting the willingness of employees to share knowledge". The conclusions of this study show that internal and external motivational factors are more effective on attitude compared to knowledge sharing whilst attitude has an implicit and explicit impact on willingness to share knowledge among employees of Tehran Municipality. 
Xie et al. (2017) conducted a study titled "How does knowledge inertia effect a company's new product innovation?" In this study, they investigated the three components of process inertia, learning inertia and experience inertia on knowledge inertia and its relation to product innovation. The statistical sample of this research consisted of 376 top technology companies of the Yangtze region in China. The data collection tool was a questionnaire and the analysis method was structural equation modelling. The results of this study confirmed the significant effect of knowledge inertia and its components on product innovation.

Kokanuch, A. and Tuntrabundit, K. (2017) conducted a study titled "Knowledge sharing capabilities in health organizations". Their objective was to investigate the effect of organizational culture and stakeholder expectations on the relationship between organizational factors and knowledge sharing capabilities. The data collection tool was a questionnaire and the analysis method was structural equation modelling. The conclusions of this research show that organizational culture has a positive effect on the relationship between organizational atmosphere and knowledge integration whilst stakeholder expectations has a positive effect on the relationship between organizational atmosphere and knowledge change.

Moon et al. (2017) conducted a study titled "Corporate strategic learning capabilities: an expansion on dimensions." In this study they aimed to extract learning capabilities' dimensions. They extracted a model of seven components consisting of external focus, strategic dialogue, strategic involvement, customer centered strategy, theoretical imagination, empirical learning and reflective accountability. They used the factor analysis method for evaluations. Finally, their model was validated.

\section{Conceptual research model}

In the current study, the knowledge inertia model by Xie et al. (2015), the knowledge sharing capabilities model by Kokanuch and Tuntrabundit (2917), and the corporate strategic learning capabilities by Moon et al. (2017) were used. The researcher of this study utilized the aforementioned models to create the following conceptual model and suggested his hypotheses on this basis: 


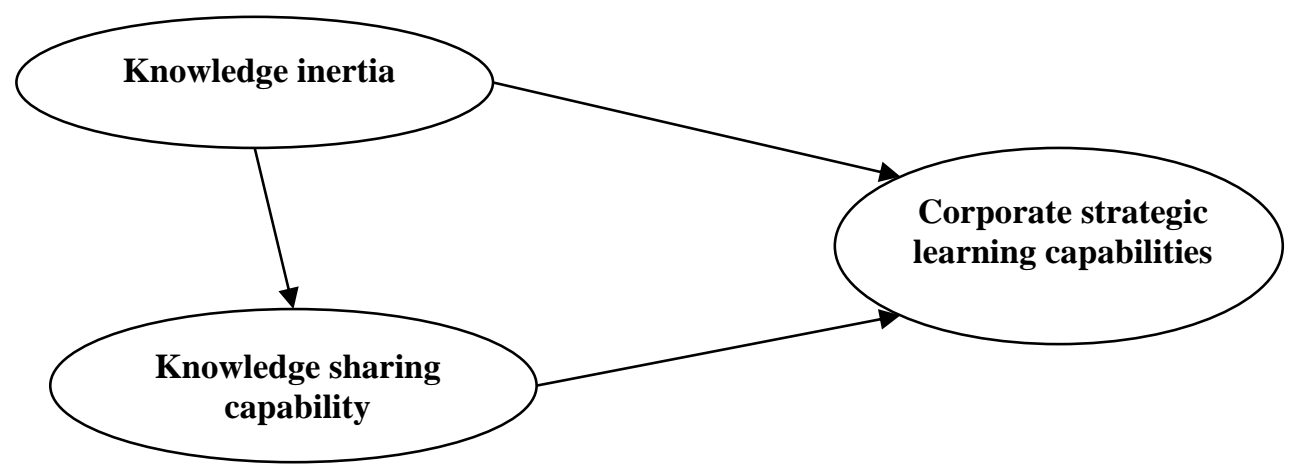

Figure 1: operational research model

\section{Research hypothesis}

1- Knowledge inertia has a significant effect on corporate strategic learning capabilities of National Bank branches in Hamedan Province.

2- Knowledge sharing capabilities has a significant effect on corporate strategic learning capabilities of National Bank branches in Hamedan Province.

3- Knowledge inertia has a significant effect on knowledge sharing capabilities of National Bank branches in Hamedan Province.

\section{Research methodology}

The present study serves a practical purpose. Moreover, since the study is a description of the status quo, it is considered a descriptive study which has been conducted at a specific time interval, thus it is a cross-sectional research. Nevertheless, due the use of quantitative data, this research can be considered a quantitative research. The statistical population of this research consists of all employees of National Bank branches in Hamedan Province which is 602 individuals. A sample of 240 members was selected based on the Krejcie and Morgan table.

The present study used a questionnaire for data collection. Three questionnaires were used which are mentioned further. The standard knowledge inertia questionnaire by Xie et al. (2015) consisting of nine questions and the three components of process inertia, learning inertia, and experience inertia, the standard knowledge sharing capabilities questionnaire by Kokanuch and Tuntrabundit (2017) consisting of nine questions and three components of knowledge sharing preparedness, knowledge change and knowledge completion, the standard corporate strategic learning capabilities by Moon et al. (2017) consisting of twenty one questions and seven components of external focus, strategic dialogue, strategic involvement, customercentered strategy, theoretical imagination, empirical learning and reflective accountability. In 
order to determine research validity, the content validity index was used and Cronbach's alpha was implemented to determine research reliability. Table 1 presents Cronbach's coefficients. As presented in this table, the Cronbach's alpha values for all components exceed the recommended value of 0.7 . Thus, the research questionnaires are of acceptable reliability. The CVCI index for the other variables are as follows:

Table 1: content validity index CVCI for studied variables

\begin{tabular}{|c|c|}
\hline Variable & CVCI value \\
\hline Knowledge inertia & 90 \\
\hline Knowledge sharing capabilities & 90 \\
\hline Strategic learning capabilities & 90 \\
\hline
\end{tabular}

It is noteworthy that the higher the validity coefficient, the higher the content validity (Heydari Charudeh, 2010, 57-59).

Table 2: Cronbach's alpha values for knowledge inertia questionnaire

\begin{tabular}{|c|c|c|c|}
\hline Variables & $\begin{array}{c}\text { Number of } \\
\text { questions }\end{array}$ & $\alpha$ & Reliability status \\
\hline $\begin{array}{c}\text { Knowledge inertia } \\
\text { questionnaire }\end{array}$ & 9 & 0.833 & Reliable \\
\hline $\begin{array}{c}\text { Knowledge sharing } \\
\text { capabilities questionnaire }\end{array}$ & 9 & 0.788 & Reliable \\
\hline $\begin{array}{c}\text { Corporate strategic learning } \\
\text { capabilities questionnaire }\end{array}$ & 21 & 0.905 & Reliable \\
\hline
\end{tabular}

If Cronbach's alpha coefficient exceeds the value of 0.7 , the test is of acceptable reliability (Momeni and Fa'al Ghayumi, 2010, 212). Hence, the current test is of acceptable reliability.

\section{Research results}

Prior to data analysis, their distribution status was assessed using the KolmogorovSmirnov test and it was clarified that variable distribution was not normal. Thus, the partial least squares method was used which is executable using the SmartPLS software. The following figures depict the hypothesis estimation amidst the estimation of path coefficients and significant coefficients. 


\section{Structural path coefficients of research hypothesis}

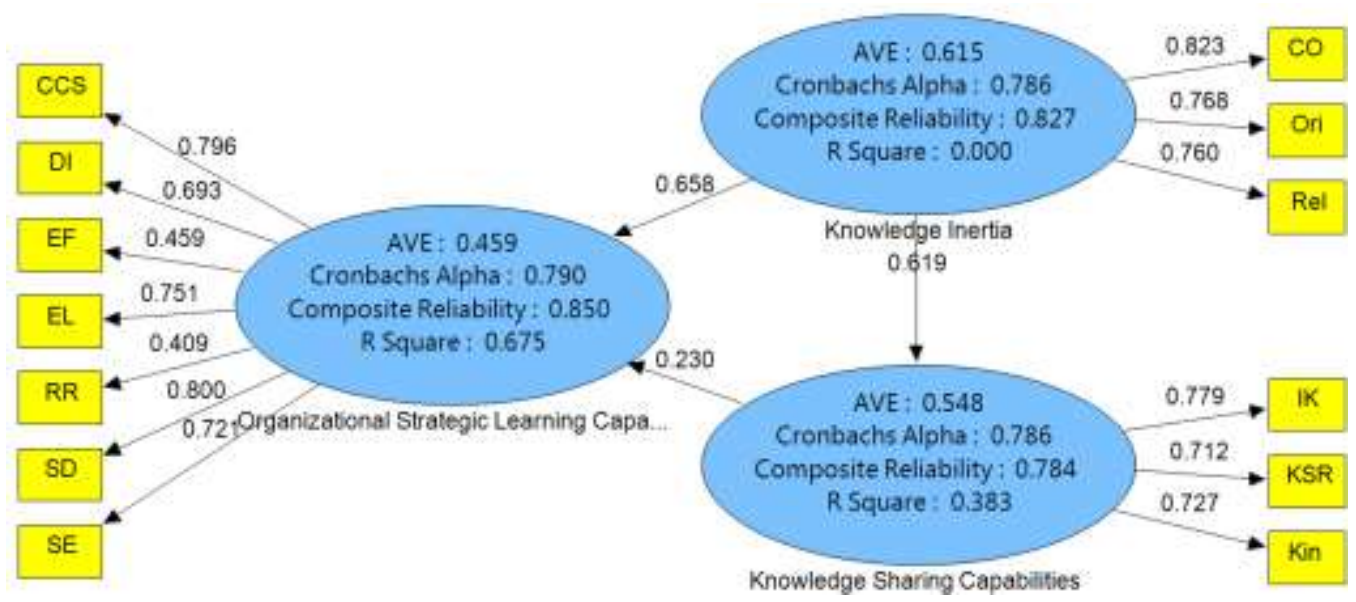

Figure 2: Path coefficients estimation of main hypothesis

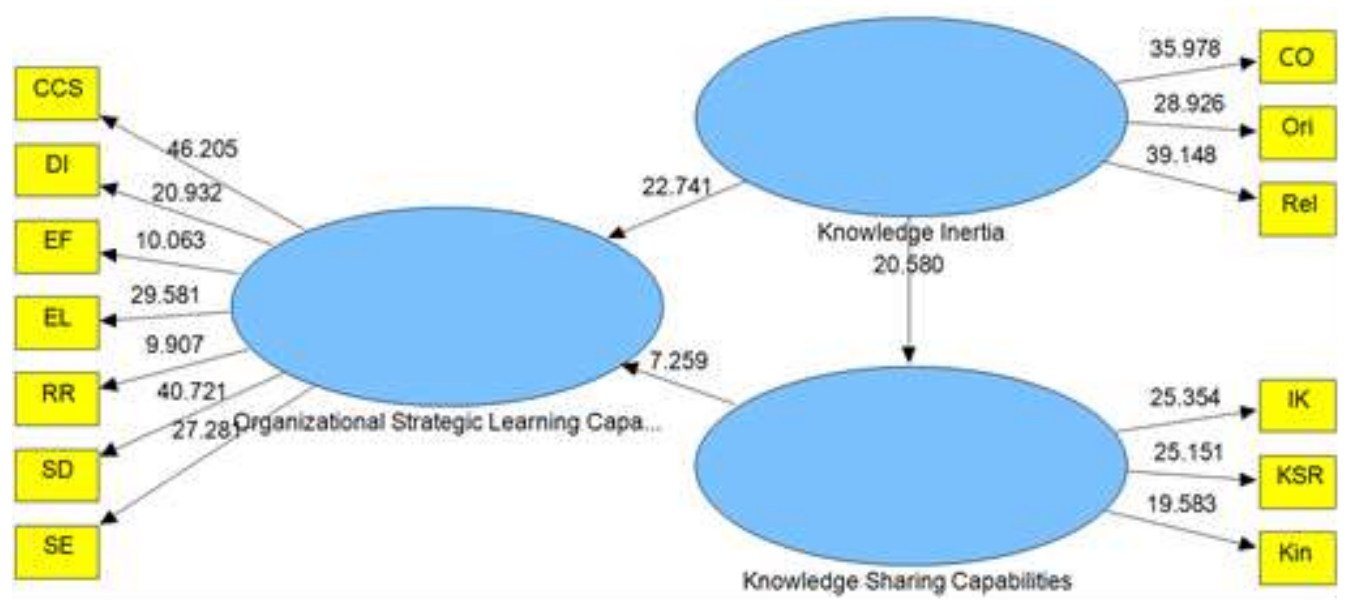

Figure 3: t-values estimation of main hypothesis

Table 3: t-values and structural path model coefficients of main hypothesis

\begin{tabular}{|c|c|c|c|c|c|c|c|c|c|}
\hline Hypothesis & Paths & $\beta$ & $N D E$ & $T E$ & $r^{2}$ & $\alpha$ & $P$ & $\begin{array}{c}t- \\
\text { value }\end{array}$ & Result \\
\hline 1 & $\begin{array}{c}\text { Knowledge inertia-strategic learning } \\
\text { capabilities }\end{array}$ & 0.658 & 0.143 & 0.801 & 0.43 & & & 22.741 & Approved \\
\hline 2 & $\begin{array}{c}\text { Knowledge inertia-knowledge sharing } \\
\text { capabilities }\end{array}$ & 0.619 & --- & 0.619 & 0.38 & 0.05 & 0.95 & 20.580 & Approved \\
\hline 3 & $\begin{array}{c}\text { Knowledge sharing capabilities — strategic } \\
\text { learning capabilities }\end{array}$ & 0.230 & --- & 0.230 & 0.05 & & & 7.259 & Approved \\
\hline
\end{tabular}

As shown in the above table, the path coefficients of all main hypothesis are significant. Given the above table, it can be stated that because the $\mathrm{t}$-values of all main hypothesis exceed 1.96, there is no evidence for rejection and their path coefficients are significant, thus the hypotheses are approved. Researchers whom utilize structural path modelling must initially 
evaluate the hypothetical direct paths and then consider other analyzes, including mediated and moderate effects. Thus, the total direct and indirect effects of a provided variable on another variable must be interpreted and evaluated. Evaluating only the direct effect is not sufficient even if such direct effect is extremely significant. The knowledge inertia variable exhibits an indirect effect of 0.143 on strategic learning capabilities. In structural path modeling it is necessary to examine the quality indices of the estimated models upon evaluating and testing the hypotheses. Structural path modeling consists of three types of fit indices including exterior model fit index, internal model fit index, and whole model fit index. The following table shows the aforementioned indices.

Table 4: Evaluation of internal, external and whole model index of the main hypotheses

\begin{tabular}{|c|c|c|c|c|c|c|c|c|}
\hline \multirow[t]{2}{*}{ Variables } & \multicolumn{3}{|c|}{ External model index } & \multicolumn{2}{|c|}{$\begin{array}{c}\text { Internal } \\
\text { model index }\end{array}$} & \multicolumn{3}{|c|}{ Whole model index } \\
\hline & $\alpha$ & $\rho$ & $A V E$ & $r^{2}$ & ${ }^{2} Q$ & Com & Red & $G O F$ \\
\hline Knowledge inertia & 0.786 & 0.826 & 0.615 & --- & 0.615 & 0.615 & --- & \\
\hline $\begin{array}{l}\text { Knowledge sharing } \\
\text { capabilities }\end{array}$ & 0.786 & 0.783 & 0.547 & 0.383 & 0.209 & 0.547 & 0.209 & 0.52 \\
\hline $\begin{array}{l}\text { Strategic learning } \\
\text { capabilities }\end{array}$ & 0.790 & 0.849 & 0.5 & 0.675 & 0.307 & 0.5 & 0.285 & \\
\hline
\end{tabular}

As shown by the table above, the Cronbach's alpha and composite reliability values exceed the recommended 0.7 value. The AVE values also exceed the assumed value of 0.5 . Thus, the exterior models are of suitable fit. The $r^{2}$ index show that the predictor variables have predicted the dependent values to a significant extent. Since the $\mathrm{Q}^{2}$ index is greater than 0 , it can be stated that there is a prediction relation. Moreover, the common index exceeds the assumed value of 0.5 and the redundancy index is not 0 . This indicates a suitable fit of the research model for the main hypotheses. The GOF index also shows that the model exhibits up to $52 \%$ predictability.

\section{Discussion and conclusion}

The present research was aimed to address the effects of knowledge inertia on corporate knowledge sharing capabilities and strategic learning capabilities. The evaluation results showed that knowledge inertia has a significant effect on corporate strategic learning capabilities. The extent of effect exerted on corporate strategic learning capabilities is 0.658 and the $t$-value is 22.741 , which is statistically significant at 0.95 confidence level and 0.05 
error margin, since this value exceeds 1.96. In other terms, it can be expected that for every increased unit of knowledge inertia, the corporate strategic learning capabilities variable will increase by $(0.658)^{2} /=0.43$ unit. Evidence suggests that this level of effect is also significant at a level higher than $1 \%$, which indicates the significant effect of the knowledge sharing variable on corporate strategic learning capabilities.

According the structural path modelling results, it can be stated that knowledge sharing capabilities have a significant effect of 0.230 and $t$-value $=7.259$ on corporate strategic learning capabilities. The path coefficient value of 230.0 in a sample size of 384 members is considered significant. On this basis, there is evidence to approve the hypotheses.

Evaluations of the third main hypotheses show that knowledge inertia has a significant effect of 0.619 ( $\mathrm{t}$-value=20.580) on knowledge sharing capabilities. With a path coefficient of 0.619 and t-statistic that exceeds the assumed value of 1.96 at 0.95 confidence level and 0.05 error margin, the acceptance of this hypothesis is approved.

Based on the results of these hypotheses, it is recommended that the organization should reduce learning inertia by encouraging individuals to acquire and learn new methods and ideas and to support employees to avert experience inertia. The organization must aim to encourage individuals to learn new knowledge and explore new approaches and ideas. The sharing of knowledge and experience of organization members should enhance and improve experience inertia and create a win-win situation for both individuals and the organization. The organization's managers should inspire individuals to change their conventional behavior and thinking process, use initiatives to seek new knowledge resources and accept suggestions on new problem-solving methods. They should also create an atmosphere within the organization which enables members to feel secure about sharing ideas, constructive criticism, acquiring mental help for one another and changing conventional work methods. When organization members face time constraints in knowledge acquisition and distribution, they should prioritize information and select the most important ones. Organization managers should provide the required technological means for knowledge acquisition and distribution within the organization.

1. Since knowledge sharing is an influential factor on strategic learning capabilities, it is favorable to enhance knowledge sharing within the organization by empowering employees whilst building trust and interdependence among members.

2. Enhanced interactions among individuals as well the improvement and facilitation of communications results in enhanced trust and dependency among members of the 
organization. Thus, creating the grounds to form informal groups and the implementation of non-work related schemes will enable greater knowledge and information exchange among individuals.

3. Given the time-consuming nature of the process of building trust and dependency among individuals and the importance of providing the means for such objectives, managers should plan to create and promote a culture of shared values to improve trust and dependency within the organization.

4. It is recommended to identify and appease existing barriers and hindering knowledge sharing factors in universities.

\section{Recommendations from third hypothesis test}

1. In line with appeasing organizational stagnation and inertia, it is recommended that the organization trains employees not to utilize their past knowledge and experience in dealing with new and unprecedented issues.

2. In confronting inertia, it is evident that individuals often do not utilize new knowledge to resolve new issues, hence their problem-solving methods lack innovation whilst mostly relying on previous and obsolete knowledge and experience. Thus, it is recommended to utilize creative and innovative approaches to resolve any issues.

3. Based on the study findings, it is recommended to explain the causes and factors of change in the organization to the stakeholders, since it will reduce organizational inertia in the identified dimensions of occupational status, job security and psychological defense.

4. In order to enhance organizational learning, it is recommended to reduce learning inertia by encouraging members to acquire and develop ideas, attitudes and methods.

5. The organization is recommended to aid members in increasing their work efficacy through experience inertia.

\section{References}

Aarabi M. \& Fakharian M. (2009) Measuring level of organizational learning in Iran milk industries companies. Management Research; 1(1): 109-129. [Persian].

Aslanlou, B.; Khodami, S. (2017) The effect of knowledge inertia and entrepreneurial intensity on brand performance, commercial management perspective, $2^{\text {nd }}$ edition, pages $45-62$ 
Bhatnagar, J. (2006), "Measuring organizational learning capability in Indian managers and establishing firmperformance linkage”, The Learning Organization. Vol. 13, No. 5, pp. 416433.

Dooley, L. and Sullivan, D.O. (2003) "Developing a software infrastructure to support systematic innovation through effective management", Technovation, vol. 23, p. 689-704.

Hajian, E.; Sardar, S. The provision of a template to measure influential internal and external motivational factors on employees' willingness to share knowledge, Scientific Research Journal, Institute of Information Science and Technology of Iran, 32nd edition, number 4, pages 1118-1093.

Heydari, H.; Mousavi, F.; \& Hosni, S. (2016), Design of a human resources structural model to achieve organizational loyalty, Tehran University government management, 5th edition, number 3, pages 375-380.

Heydari, S.; Sadeghi, T.; Vanaki, Z.; Khosruanjam, M.; \& Rudini, A. (2014), Organizational learning capabilities for nurses, Nursing Management Journal, second year, number 4, pages 56-63.

Hoseini, M.; Sadeghi A. F. \& Hosani, F.(2014), Assessment of the relationship between knowledge inertia, knowledge management and organizational innovation, case study: small and medium software companies of Yazd Province, Sixth conference on knowledge management, Tehran, Institute of Oil, Gas and Petrochemicals Information https://www.civilica.com/Paper-IKMC06-IKMC06_313.htm

Kokanuch, A. and Tuntrabundit, K. (2017) "Knowledge sharing capability in healthcare organizations", Journal of Asia Business Studies, Vol. 11 Issue: 2, pp.135-151, https://doi.org/10.1108/JABS-10-2015-0183

Kordnaeej, A. A., Danayi Fard, H., Delkhah, J. \& Aghaziyarati, M. (2013). Strategic renewal: investigating the role of organizational learning. Journal of Business Management Vision, 12(15), 37-57. (In Persian)

Liao , Shu-h Sien; Fei, Wu-Chen; Liu, Chih- Tang (2008), Relationships betweenknowledge inertia, organizational learnig and organization innovation; Technovation 28, pp: 183-195.

Liao S. H. (2002) "Problem solving and knowledge inertia"; Expert Systems with Applications, 22:21-31.

Liao Shu-h sien, Fei Wu-chen, Liu chih- Tang (2008) "Relationships between knowledge inertia, organizational learning and organization innovation"; Technovation 28, pp: 183-195.

Liao, S. H. , Fei, W. C. , Chen, C. C. (2007), Knowledge sharing, absorptive capacity, and innovation capability: an empirical study on Taiwans knowledge intensive industries; Journal of Information Science 33 (3), pp: $340^{\circ} 359$.

Lin, Hsiu- Fen \& Lee, Gwo-Guang (2004). Perceptions of Senior Managers Toward Knowledge Sharing Behavior, Management Decision. 42(1), pp. 108-125.

Lin, Hsiu-Fen (2007). Knowledge Sharing and firm Innovation Capability: An Empirical Study. International Journal of Manpower, 28(3/4), pp. 315-332.

Lin, T. C., Wub, S., \& Lu, C.T. (2012) Exploring the affect factors of knowledge sharing behavior: The relations model theory perspective, Expert Systems with Applications, 39, Pp. 751-764

Lin, W.B. (2008) The effect of knowledge sharing model, Expert Systems with Applications, 34, Pp. 1508-1521

Lin, Wen-Bao. (2008). The Exploration Factors of Affecting Knowledge Sharing The case of Taiwan's High-tech Industry. Expert Systems with Applications, 35(3), pp. 661-676. 
Moenaert, R.K., Caeldries, F., Lievens, A. and Wauters, E., 2000, "Communication flows in international product innovation teams", Journal of Product Innovation Management,Vol. 17 No. 5, pp. 360-77.

Moon, H.; Ruona, W.; Valentine, T. (2017) "Organizational strategic learning capability: exploring the dimensions", European Journal of Training and Development, Vol. 41 Issue: 3, pp.222-240, https://doi.org/10.1108/EJTD-08-2016-0061

Peaen M, Redrik K, Malroony C. (2005) Learning organizations in practice. [Trans.;A. Lamei]. Shahed\&Isargar publication. UromiaUniversity of Medical Sciences. [Persian].

Rahnavard, F.; Qasemi, M..(2009), The effect of corporate structure, corporate culture and IT application on knowledge sharing in executive bodies of Esfahan City, Management and Development Process Scientific-Research Journal, 22 ( 1 and 2), pages 34-58.

Rosen, B., Furst, S., \& Blackburn, R., (2007) Overcoming barriers to knowledge sharing in virtual teams, Organizational Dynamics, 36, 3, Pp. 259-273.

Sepahvand, R.; Arefnejad, M.; \& Shariatnejad, A. (2016), Identification and prioritization of factors causing organizational inertia using the fuzzy Delphi method, Modern studies in decision making, edition 2, number 1, pages 95-117.

Shahbi, M. \& Jalilian, H. (2012), Assessment of the relationship between knowledge inertia, organizational learning and organizational innovation (case study: West Oil and Gas Company), Oil Industry Management and Human Resources Scientific-Research Journal, $4^{\text {th }}$ year, number 15 , pages $137-158$.

Smith, R. (2001). "A roadmap for knowledge management", Journal of Knowledge Management, Vol. 8 No. 3, p. 6-16. Sobhaninejad, M.; Sahaei, B.; Yuzbashi, A.(2006), Learner organization, Tehran, first edition, Yastarun Publications.

Sobhaninejad, M.; Sahaei, B.; Yuzbashi, A. (2006), Learner organization, Tehran, first edition, Yastarun Publications.

Xie, X., Fanga, L., Zeng, S. \& Huo, J. (2015). How does knowledge inertia affect firms' product innovation? Journal of Business Research, 69, 1615-1620.

Yukl, G. (2009), "Leading organizational learning: Reflections on theory and research", The Leadership Quarterly, Vol.20, pp.49-53. 